\title{
Dynamic behavior of coalbed methane flow along the annulus of single-phase production
}

\author{
Xinfu Liu ${ }^{1,2} \cdot$ Chunhua Liu $^{3} \cdot$ Guoqiang Liu ${ }^{4}$
}

Received: 28 February 2019/Revised: 9 September 2019/Accepted: 26 September 2019/Published online: 15 October 2019

(C) The Author(s) 2019

\begin{abstract}
Dynamic behavior of coalbed methane (CBM) flow will provide the theoretical basis to optimize production performance for a given well. A mathematical model is developed to simulate flowing pressures and pressure drops of CBM column from well head to bottom hole. The measured parameters and independent variables of flow rates, flowing pressures and temperatures are involved in CBM producing process along the annulus. The developed relationships are validated against full-scale measured data in single-phase CBM wellbores. The proposed methodology can analyze the dynamic behavior in CBM reservoir and process of CBM flow with an overall accuracy of $2 \%$. The calculating process of flowing pressures involves friction factor with variable Reynolds number and CBM temperature and compressibility factor with gravitational gradients. The results showed that the effect of flowing pressure on CBM column was more obvious than that on CBM and water column accompanied by an increase of dynamic water level. The ratios of flowing pressure on increment of CBM column to the whole column increased with the declined flow rates of water column. Bottom-hole pressure declined with the decreased flowing pressure of CBM column along the annulus. It will lead to the results of the increased pressure drop of CBM column and CBM flow rate in single-phase CBM wellbores.
\end{abstract}

Keywords Dynamic characteristic $\cdot$ Single-phase CBM wellbore $\cdot$ Flowing pressure of CBM column $\cdot$ Flow rate of CBM column

Chunhua Liu

20090053@upc.edu.cn

1 School of Mechanical and Automotive Engineering, Qingdao University of Technology, Qingdao 266520, Shandong, China

2 Key Lab of Industrial Fluid Energy Conservation and Pollution Control (Qingdao University of Technology), Ministry of Education, Qingdao 266520, Shandong, China

3 College of Mechanical and Electronic Engineering, China University of Petroleum (East China), Qingdao 266580, Shandong, China

4 PetroChina Coalbed Methane Co., Ltd. Linfen Branch, Taiyuan 041000, Shanxi, China

\section{Introduction}

Periodic analysis of flowing pressures can forecast the dynamic behavior in coal reservoirs and solve the common problems of matching the CBM reservoir behavior with wellbore conditions in single-phase CBM wellbores (Mitchell 2011; Mohammed and Enty 2013; Towler et al. 2016). A reliable and accurate approach to predict flowing pressures is essential to design artificial lifting systems and to optimize production performance for the given CBM well. An alternative is to propose a reliable and accurate approach and estimate the flowing pressures and pressure drops in single-phase CBM wellbores with respect to the well liquids and well datum (Osman et al. 2005; Bello and Asafa 2014). In order to calculate the flowing pressures, Rendeiro and Obeida (Rendeiro and Kelso 1988; Obeida and Mosallam 2007) developed the Average Temperature and Pressure method. And Z-factor could be computed by 
assuming the whole wellbore to be at an average temperature and pressure along the annulus. This methodology does not perform well for most deep CBM wells and is even less reliable for such CBM wells at low gas/liquid ratios. Cullender et al. (Cullender and Smith 1956; Peffer et al. 1988; Guzman et al. 2014) proposed Cullender and Smith methodology for the single-phase well with gas occupying the wellbore. This methodology took the variations in temperature and gas compressibility with depth into account. And the absolute roughness of rough-turbulent flow was $6.0 \times 10^{-4}$ inches in dry-gas wells. Wang et al. (2014) calculated the flowing pressures and pressure distributions using experimental and numerical simulations. The distributions of temperature and pressure on the bottom of the hole during the $\mathrm{SC}-\mathrm{CO}_{2}$ jet drilling were simulated experimentally and numerically, and the impacts of the nozzle diameter, the jet length, and the inlet pressure of the $\mathrm{SC}-\mathrm{CO}_{2}$ jet were analyzed. Artificial neural networks (ANN) (Osman and Aggour 2002; Mohammadpoor et al. 2010; Li et al. 2017) create models that can recognize highly complex and non-straight-forward problems. ANN provides an integrated approach for the prediction of bottom-hole pressures in multiphase flow. Ashena and Menad (Ashena and Moghadasi 2011; Menad et al. 2018) estimated the flowing pressures using evolved neural networks and grey wolves optimization. ANN with 7 neurons in its hidden layer was utilized to solve the non-straightforward problem of two-phase flow in annulus. Much more promising results were obtained when the highly efficacious tool of ant colony optimization (ACO) was utilized as the next method to optimize the weights and thresholds of the neural networks. The models were developed and tested using 100 field data collected from Algerian fields and covering a wide range of variables. The main problem that ANN models suffer from, is the presence of some inaccuracies caused by the defaulted training algorithms that trap in local minima.

The above relationships generally conducted various theoretical analytic approaches of conventional oil fields and dry-gas wells to calculate the flowing pressures and pressure drops. Therefore, these modeling procedures do not give the desired results to predict the flowing performance along the annulus. The main reason is that there exists the differences between coal geology and gas formations (Yao and Ge 2011; Liu 2013; Liu et al. 2018; Underschultz et al. 2018), including low water production, high dynamic water level, short stroke and rapid dropping down of pumping speed. Another aspect to consider is that the flowing pressures in CBM wellbores have not been further developed and the available models cannot satisfy the accuracy requirements in engineering design.

A mathematical model is developed to simulate flowing pressures and pressure drops of CBM column from well head to bottom hole. The measured parameters and independent variables of flow rates, flowing pressures and temperatures were involved in CBM producing process along the annulus. The flowing pressures were predicted on the basis of single-phase CBM wellbore conditions along the annulus stretching over a wider range in order to predict the dynamic characteristics of CBM flow in single-phase CBM wells and provide the theoretical basis to design artificial lifting systems.

\section{Model development of CBM flow}

This work presents a methodology that involves a numerical integration technique to calculate flowing pressures of CBM column based on the gas flow equation and well flowing model. And the methodology would provide accurate results while it involves friction factor with variable Reynolds number and CBM temperature and compressibility factor with gravitational gradients. The relationship about energy among the tubing, casing and their annulus in single-phase CBM wellbore stems from the mechanical energy equation. This energy balance (Mattar and McNeil 1998; Mohammed et al. 2011) can be expressed for steady-state flow, as follows:

$\frac{\mathrm{d} p}{\mathrm{~d} L}=g \rho \sin \theta+0.5 \frac{f \rho}{d} v^{2}+\rho v \frac{\mathrm{d} v}{\mathrm{~d} L}+\rho \frac{\mathrm{d} w}{\mathrm{~d} L}$

where $d$ is the diameter of CBM column in $\mathrm{m}, f$ is the friction factor along the annulus, $L$ is the length of whole wellbore in $\mathrm{m}, p$ is the pressure of CBM column in $\mathrm{Pa}, v$ is the flowing velocity of CBM column in $\mathrm{m} / \mathrm{s}, \theta$ is the angle of CBM column in rad, and $\rho$ is the density of CBM column in $\mathrm{kg} / \mathrm{m}^{3}$.

Two parameters are introduced to calculate pressures of CBM column. They are the flowing velocity and density of CBM column in single-phase CBM wells.

$v=5.094 \times 10^{-6} \frac{Z q_{s c} T}{d^{2} p}$

$\rho=3.485 \times 10^{3} \frac{\gamma_{c} p}{Z T}$

Considering CBM column flow from the bottom hole to well head along the annulus between tubing and casing, the kinetic energy loss is ignored in the energy balance. The energy balance for calculating pressure of CBM column can be expressed as follows:

$\frac{\mathrm{d} p}{\mathrm{~d} h}+3.419 \times 10^{4} \gamma_{c} \frac{p}{Z T}+4.520 \times 10^{-8} \frac{\gamma_{c} f}{d^{5}} \frac{Z T}{p} q_{s c}^{2}=0$

where $h$ is the coordinate of well depth in $\mathrm{m}, q_{s c}$ is flow rate of CBM column in $\mathrm{m}^{3} / \mathrm{d}, T$ is the temperature along CBM 
column in $\mathrm{K}, Z$ is compressibility factor of CBM column, and $\gamma_{c}$ is specific gravity of CBM column.

The estimation of pressures of CBM column involves the energy losses of friction resistance and the hydrostatic head in CBM wellbore. Upon transformation of variable and integration, the energy equation can be simplified to the following pressure formula.

$$
3.418 \times 10^{-2} \gamma_{c} h_{c}=\int_{p_{h f}}^{p_{t c f}} \frac{Z p T}{p^{2}+1.322 \times 10^{-18} Z^{2} f d^{-5} q_{s c}^{2} T^{2}} \mathrm{~d} p
$$

The CBM column flows upward along the annulus between tubing and casing, and hence the flowing velocity of CBM column is given by the formula, as follows:

$v=\frac{4 q_{s c}}{\pi\left(d_{c}^{2}-d_{t}^{2}\right)}$

Consequently, the energy equation can be modified to the following equation, which is used in computing of pressure of CBM column in single-phase CBM wellbores.

$\gamma_{c} h_{c}=\int_{p_{h f}}^{p_{t c f}} \frac{29.257 Z p T}{p^{2}+\frac{1.322 \times 10^{-18} Z^{2} f q_{s}^{2} T^{2}}{\left(d_{t}+d_{c}\right)^{2}\left(d_{c}-d_{t}\right)^{3}}} \mathrm{~d} p$

where $d_{c}$ is the casing diameter in $\mathrm{m}, d_{t}$ is the tubing diameter in $\mathrm{m}, h_{c}$ is the well depth of the whole CBM column in $\mathrm{m}, p_{h f}$ is the well-head pressure in $\mathrm{MPa}$, and $p_{\text {tcf }}$ is the flowing pressure on dynamic water level in singlephase CBM wellbores in MPa.

compressibility factor of CBM column, $Z$, illustrates the ratio of true volume to ideal volume under the condition of identical quality. This factor can be obtained from Sanding-Katz curves of compressibility factor. The factor is known as a function of pseudoreduced density, $\rho_{p r}$, and pseudoreduced temperature, $T_{p r}$, for the pure CBM column. An explicit factor, which is an accurate mathematical approximation (Sutton 2008; Mora and Wattenbarger 2009), is developed due to experimental results and given by:

$$
\begin{aligned}
& Z= \frac{0.299-2.188 \times 10^{-2} \gamma_{c}-4.689 \times 10^{-3} \gamma_{c}^{2}}{\rho_{p r} T_{p r}} \\
& \exp \left[-1.2\left(\frac{T_{p r}-1}{T_{p r}}\right)^{2}\right] \\
& T_{p r}=103.89+183.33 \gamma_{c}-39.722 \gamma_{c}^{2}
\end{aligned}
$$

The CBM flow through the annulus between tubing and casing in single-phase CBM wells always results in some energy losses. These losses are mainly caused by the friction related to pipe roughness and viscosity effects. Since the friction losses cannot be measured directly, the correlation is proposed to determine the friction factor (Yalniz and Ozkan 2001; Langelandsvik et al. 2005). This factor is a function of both relative roughness in wellbore and Reynolds number (Yalniz and Ozkan 2001; Langelandsvik et al. 2005) of CBM column. Relative roughness in wellbore is usually described in terms of the ratio of absolute roughness, $e$, to annulus diameter $\left(d_{c}-d_{t}\right)$. This corresponds to the absolute roughness of the annulus in CBM wellbores and has been proved to be experimentally correct for different test CBM columns based on the laboratory investigation. Therefore, an explicit correlation for the friction factor of CBM column in pumping wellbores is developed, and can be given by:

$f^{-0.5}=1.14-2 \lg \left(\frac{e}{d_{c}-d_{t}}+\frac{21.25}{R e^{0.88}}\right)$

Since Newtonian viscous force is related to the lubrication perimeter, Reynolds number $(R e)$ of CBM column in the annulus of single-phase CBM wells can be determined, as follows:

$R e=1.78 \times 10^{-5} \frac{q_{s c} \gamma_{c}}{\mu_{c}\left(d_{t}+d_{c}\right)}$

where $\mu_{c}$ is the viscosity of flowing CBM column in $\mathrm{mPa}$ s.

The integrand of pressure drop, $I$, is introduced and it is defined as follows:

$I=\frac{\frac{p}{Z T}}{\left(\frac{p}{Z T}\right)^{2}+1.32 \times 10^{-18} \frac{q_{s c}^{2} f}{\left(d_{c}-d_{t}\right) \cdot\left(d_{c}^{2}-d_{t}^{2}\right)^{2}}}$

The mathematical model of flowing pressures for CBM column is solved with numerical integration due to the numeric analysis. And the procedure involves iterative calculations with regard to two parts of CBM column in single-phase CBM wells.

$$
\begin{aligned}
6.84 \times 10^{-2} \gamma_{c} h_{c}= & \left(p_{m f}-p_{h f}\right)\left(I_{m f}+I_{h f}\right) \\
& +\left(p_{t c f}-p_{m f}\right)\left(I_{t c f}+I_{m f}\right)
\end{aligned}
$$

For the mathematical model of upper pressure of CBM column, the flowing pressure for middle part of the whole CBM column, $p_{m}$, can be determined due to the measurements of well-head pressure in single-phase CBM wells. And then the equation for upper pressure of CBM column can be given by:

$3.42 \times 10^{-2} \gamma_{c} h_{c}=\left(p_{m f}-p_{h f}\right)\left(I_{m f}+I_{h f}\right)$

The mathematical model can be solved for upper pressure of CBM column, as follows:

(1) Calculate the integrand $I_{h f}$ and the product of $\gamma_{c}$ and $h_{c}$ in single-phase CBM wellbores.

(2) Complete the initial computation with the help of the integrand $I_{m f}$ equal to $I_{h f}$.

(3) Determine the flowing pressure, $p_{m}$, and the integrand, $I_{m f}$, for the middle part of the whole CBM column in single-phase CBM wells. 
(4) Iterate by returning to Step 3 until the accurate result of $p_{m f}$ is obtained.

For the mathematical model of lower pressure of CBM column, the flowing pressure on dynamic water level in single-phase CBM wellbores, $p_{t c f}$, can be determined due to the results of pressure for middle part of the whole CBM column along the annulus. And then the equation for lower pressure of CBM column can be given by:

$p_{t c f}=p_{h f}+\Delta p_{c}=p_{h f}+\frac{0.205 \gamma_{c} h_{c}}{I_{h f}+4 I_{m f}+I_{t c f}}$

The mathematical model can be solved for lower pressure of CBM column, as follows:

(1) Complete the initial computation with the help of the integrand $I_{b f}$ equal to $I_{m f}$.

(2) Determine the flowing pressure, $p_{t c f}$, and the integrand, $I_{t c f}$, on dynamic water level in wellbores.

(3) Iterate by returning to Step 2.

The flowing pressure on dynamic water level in singlephase CBM wellbores, $p_{t c f}$, can be iterated as the sum of pressure of well head and CBM column. Repeat the above procedure until the desired accuracy of $p_{t c f}$ is obtained.

\section{Flowing pressures in single-phase CBM wellbores}

The complete CBM producing process can be divided into several phases including single-phase water flow, twophase (CBM and water) flow and single-phase CBM flow (Okuszko et al. 2008; Liu et al. 2011, 2019; Sugiarto et al. 2015). Undersaturated coal reservoirs may produce water mainly for a substantial period of time until desorption pressure is reached (Lyubarskii and Ivanov 1989; Boltenko 2013; Smith et al. 2019). And then the coal reservoirs produce water mostly and little CBM and exhibit single-phase water flowing performances (Vicki and Paul 2002; Clarkson et al. 2007; Liu et al. 2017; Fan et al. 2019). Therefore, the bottom-hole pressures are affected by well-head pressure, pressure drops of CBM column and water column in producing wellbores for single-phase water flow. The CBM column flows upward while the water column flows downward along the annulus between tubing and casing. And hence the flowing pressures can be found by the CBM and water flow formulae.

The flowing pressure for middle part of the whole CBM column, $p_{m f}$, can be calculated due to the measurements of well-head pressure in single-phase water wellbores, as follows:

$p_{m f}=p_{h f}+3.42 \times 10^{-2} \frac{\gamma_{c} h_{c}}{I_{m f}+I_{h f}}$
The flowing pressure on dynamic water level in singlephase water wellbores, $p_{s c f}$, can be determined based on the results of pressure for middle part of the whole CBM column, as follows:

$p_{s c f}=p_{h f}+0.205 \frac{\gamma_{c} h_{c}}{I_{h f}+4 I_{m f}+I_{s c f}}$

As shown in Fig. 1, bottom-hole pressure of singlephase water flow, $p_{b f}$, can be determined as the sum of well-head pressure, $p_{h}$, flowing pressure of CBM column, $\Delta p_{c}$, and flowing pressure of water column, $\Delta p_{w}$, in pumping wellbores.

$$
\begin{aligned}
p_{b f} & =p_{h f}+\Delta p_{c}+\Delta p_{w} \\
& =p_{h f}+0.205 \frac{\gamma_{c} h_{c}}{I_{h f}+4 I_{m f}+I_{c f}}+\rho_{w} g h_{w}
\end{aligned}
$$

where $h_{w}$ is the well depth of water column in $\mathrm{m}$, and $\rho_{w}$ is the density of water column in $\mathrm{kg} / \mathrm{m}^{3}$.

The coal reservoirs may produce CBM mostly during the phase of single-phase CBM flow (Borowsky and Wei 2006; White and Smith 2012; Tang et al. 2016). And hence the CBM wellbores exhibit single-phase flowing performances for at least a portion of their producing process. The bottom-hole pressures are affected by well-head pressure and pressure drop of CBM column in producing wellbores for single-phase CBM flow. The value of wellhead pressure can be recorded by the pressure gauges. The CBM column flows upward in the wellbore, and hence the pressure can be found by the CBM flow formulae. Knowing the values of these pressures, bottom-hole pressures of single-phase CBM wellbores, $p_{b f}$, can be

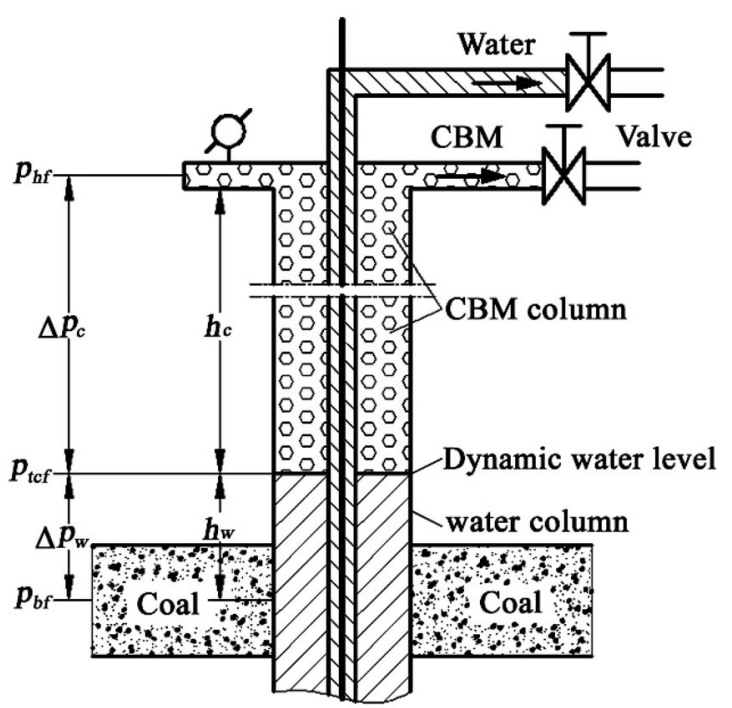

Fig. 1 The components of flowing pressures and pressure drops in single-phase CBM wells 
determined as the sum of well-head pressure, $p_{h f}$, and pressure of CBM column, $\Delta p_{c}$, in single-phase CBM wellbores.

\section{Application and interpretation}

\subsection{Field application}

The dynamic characteristics of CBM column flow are clarified by the examples of Hancheng coalfield in Ordos Basin, China. The CBM wells in Hancheng coalfield make continuous production and accumulate a lot of pumping data. The producing characteristics that might influence flowing performances in the wellbores were determined upon the single-phase flow properties.

The operational parameters were selected from the CBM wells in Hancheng coalfield, including: well depth of the whole CBM column, $430 \mathrm{~m}$; CBM langmuir pressure in coal reservoirs, $3.50 \mathrm{MPa}$; tubing diameter, $27 / 8$ in.; casing diameter, 7.0 in.; specific gravity of CBM column, 0.58 ; density of water column, $1015 \mathrm{~kg} / \mathrm{m}^{3}$; and flowing viscosity of CBM column and water column, $1.70 \times 10^{-2}$ $\mathrm{mPa} s$ and $7.85 \times 10^{-4} \mathrm{~Pa} \mathrm{~s}$, respectively.

The parameters that might influence CBM production are measured by pressure sensors, temperature sensors and flow meters. To clarify CBM producing process along the annulus between tubing and casing, the main measured parameters and independent variables are presented in Table 1. These independent variables are composed of flow rates, flowing pressures and temperatures selected in single-phase CBM wellbores.

\subsection{Results and interpretations}

To evaluate the accuracy of this proposed methodology, the predicted parameters and variables of flow rates, flowing pressures and temperatures are selected from single-phase CBM wellbores. Predicted variables of flowing pressures and pressure drops using the developed algorithm in singlephase CBM wellbores are shown in Table 2.

Predicted variables of bottom-hole pressure and the percent error between the measured and predicted total pressures in the Average Temperature and Pressure, Cullender and Smith and the proposed methodology are shown in Table 3. As a result, the maximum relative errors are determined to be $-11.2 \%,-10.4 \%$, and $-3.7 \%$, respectively. And the average relative errors are predicted to be $3.0 \%, 2.9 \%$, and $1.1 \%$, respectively. Consequently, the average relative errors can be reduced by $1.9 \%$ and $1.8 \%$ using the proposed methodology.

Table 3 shows the flowing pressures and errors for single-phase CBM wellbores using Average Temperature and Pressure methodology. And the errors are calculated between $-11.2 \%$ and $4.3 \%$. Z-factor could be computed by assuming the whole wellbore to be at an average temperature and pressure along the annulus. This methodology does not perform well for most deep and low gas/liquid ratio CBM wells.

Table 3 shows the flowing pressures and errors for single-phase CBM wellbores using Cullender and Smith methodology. And the errors are evaluated between $-10.4 \%$ and $4.8 \%$. The calculation of flowing pressures took the variations in gas compressibility and temperature with depth into account. However, this methodology was proposed for the single-phase well with gas occupying the

Table 1 Measured parameters and selected variables in single-phase CBM wellbores

\begin{tabular}{|c|c|c|c|c|c|c|c|}
\hline $\begin{array}{l}\text { Well } \\
\text { point }\end{array}$ & $\begin{array}{l}\text { Dynamic } \\
\text { water level } h_{c} \\
\text { (m) }\end{array}$ & $\begin{array}{l}\text { Flow rate of } \\
\text { CBM } q_{s c}\left(\mathrm{~m}^{3} /\right. \\
\text { d) }\end{array}$ & $\begin{array}{l}\text { Flow rate of } \\
\text { water } q_{w}\left(\mathrm{~m}^{3} /\right. \\
\text { d) }\end{array}$ & $\begin{array}{l}\text { Well-head } \\
\text { pressre } p_{h f} \\
(\mathrm{MPa})\end{array}$ & $\begin{array}{l}\text { Flowing pressure on } \\
\text { dynamic level } p_{t c h} \\
\text { (MPa) }\end{array}$ & $\begin{array}{l}\text { Measured bottom- } \\
\text { hole pressure } p_{b f} \\
(\mathrm{MPa})\end{array}$ & $\begin{array}{l}\text { Well-head } \\
\text { temperature } T_{h} \\
\text { (K) }\end{array}$ \\
\hline 1 & 160 & 6721 & 35.7 & 0.451 & 0.455 & 1.328 & 285.79 \\
\hline 2 & 338 & 6063 & 40.8 & 1.106 & 1.137 & 1.482 & 286.15 \\
\hline 3 & 389 & 5796 & 37.6 & 1.313 & 1.372 & 1.579 & 286.18 \\
\hline 4 & 396 & 5415 & 35.5 & 1.458 & 1.516 & 1.707 & 286.20 \\
\hline 5 & 402 & 4162 & 33.8 & 1.124 & 1.155 & 1.363 & 286.21 \\
\hline 6 & 418 & 4058 & 28.3 & 1.742 & 1.801 & 1.908 & 287.29 \\
\hline 7 & 426 & 3925 & 32.7 & 1.785 & 1.844 & 1.919 & 288.05 \\
\hline 8 & 431 & 3611 & 23.5 & 2.002 & 2.073 & 2.141 & 288.67 \\
\hline 9 & 436 & 3694 & 22.4 & 1.909 & 1.968 & 2.016 & 289.77 \\
\hline 10 & 439 & 3327 & 18.2 & 2.157 & 2.216 & 2.252 & 289.83 \\
\hline
\end{tabular}

Note The selected CBM wells have been investigated for many years in Hancheng coalfield 
Table 2 Predicted variables of flowing pressures and pressure drops using the developed algorithm

\begin{tabular}{lllllll}
\hline $\begin{array}{l}\text { Well } \\
\text { point }\end{array}$ & $\begin{array}{l}\text { Upper pressure of } \\
\text { CBM column } \Delta p_{u f} \\
(\mathrm{MPa})\end{array}$ & $\begin{array}{l}\text { Pressure of CBM } \\
\text { column at midpoint } \\
\Delta p_{m f}(\mathrm{MPa})\end{array}$ & $\begin{array}{l}\text { Lower pressure of } \\
\mathrm{CBM} \text { column } \Delta p_{l f} \\
(\mathrm{MPa})\end{array}$ & $\begin{array}{l}\text { Pressure of } \\
\mathrm{CBM} \text { column } \\
\Delta p_{c}(\mathrm{MPa})\end{array}$ & $\begin{array}{l}\text { Flowing pressure on } \\
\text { dynamic level } p_{t c h} \\
(\mathrm{MPa})\end{array}$ & $\begin{array}{l}\text { Column pressure of } \\
\mathrm{CBM} \text { and water } \Delta p_{t} \\
(\mathrm{MPa})\end{array}$ \\
\hline 1 & 0.0023 & 0.453 & 0.00291 & 0.0052 & 0.456 & 0.922 \\
2 & 0.0142 & 1.120 & 0.0143 & 0.0284 & 1.134 & 0.393 \\
3 & 0.0322 & 1.345 & 0.0322 & 0.0643 & 1.377 & 0.222 \\
4 & 0.0318 & 1.490 & 0.0321 & 0.0639 & 1.5220 & 0.203 \\
5 & 0.0163 & 1.140 & 0.0159 & 0.0321 & 1.156 & 0.193 \\
6 & 0.0276 & 1.770 & 0.0272 & 0.0547 & 1.797 & 0.106 \\
7 & 0.0286 & 1.814 & 0.0290 & 0.0575 & 1.843 & 0.0777 \\
8 & 0.0323 & 2.034 & 0.0318 & 0.0641 & 2.066 & 0.0666 \\
9 & 0.0271 & 1.936 & 0.0345 & 0.0616 & 1.971 & 0.0469 \\
\hline
\end{tabular}

Table 3 Predicted variables of bottom-hole pressure and relative error for single-phase CBM wellbores

\begin{tabular}{|c|c|c|c|c|c|c|}
\hline \multirow[t]{2}{*}{ Well point } & \multicolumn{2}{|c|}{ Average temperature and pressure method } & \multicolumn{2}{|c|}{ Cullender and Smith methodology } & \multicolumn{2}{|c|}{ The proposed methodology } \\
\hline & $\begin{array}{l}\text { Predicted bottom-hole } \\
\text { pressure } p_{b f}(\mathrm{MPa})\end{array}$ & Error $E(\%)$ & $\begin{array}{l}\text { Predicted bottom-hole } \\
\text { pressure } p_{b f}(\mathrm{MPa})\end{array}$ & Error $E(\%)$ & $\begin{array}{l}\text { Predicted bottom-hole } \\
\text { pressure } p_{b f}(\mathrm{MPa})\end{array}$ & Error $E(\%)$ \\
\hline 1 & 1.476 & -11.2 & 1.466 & -10.4 & 1.378 & -3.7 \\
\hline 2 & 1.540 & -3.9 & 1.547 & -4.4 & 1.527 & -3.1 \\
\hline 3 & 1.612 & -2.1 & 1.602 & -1.5 & 1.599 & -1.3 \\
\hline 4 & 1.743 & -2.1 & 1.737 & -1.8 & 1.725 & -1.0 \\
\hline 5 & 1.305 & 4.3 & 1.297 & 4.8 & 1.349 & 1.1 \\
\hline 6 & 1.887 & 1.1 & 1.873 & 1.9 & 1.903 & 0.3 \\
\hline 7 & 1.932 & -0.7 & 1.911 & 0.4 & 1.920 & -0.07 \\
\hline 8 & 2.114 & 1.3 & 2.118 & 1.1 & 2.133 & 0.4 \\
\hline 9 & 2.046 & -1.5 & 2.038 & -1.1 & 2.018 & -0.06 \\
\hline 10 & 2.279 & -1.2 & 2.284 & -1.4 & 2.261 & -0.4 \\
\hline
\end{tabular}

wellbore. And the absolute roughness of rough-turbulent flow is $6.0 \times 10^{-4}$ inches in dry-gas wells.

Comparison of flowing pressures of CBM column and bottom hole between the predicted and measured results using the proposed methodology along the annulus in single-phase CBM wellbores is shown in Fig. 2. The proposed methodology is validated against full-scale experimental data measured. The numerical results of flowing pressures of CBM column and bottom hole accord well with the experimental results in single-phase CBM wells. It can be seen from Fig. 2a, b that the maximum relative error of predicting flowing pressure of CBM column can be less than $4.7 \%$. The calculating process of flowing pressures involves friction factor with variable Reynolds number and CBM temperature and compressibility factor with gravitational gradients in single-phase CBM wells. As a result, the developed relationships can analyze the dynamic behavior in CBM reservoir and process of CBM flow with an overall accuracy of $2 \%$.

Figure 3 shows the variation of flowing pressures of well head, CBM column and CBM and water column with time in single-phase CBM wellbores. The flowing pressures along the annulus can be divided into four pressures of well-head pressure, $p_{h f}$, pressure drop of CBM column, $\Delta p_{c}$, pressure drop of CBM and water column, $\Delta p_{t}$, and bottom-hole pressure, $p_{b f}$. The flowing pressures along the annulus can fully reflect dynamic characteristics of CBM producing process because of the combination of dynamic water level and flow rates of CBM column and water column.

Figure 4 shows the variation of pressure ratios on increment of CBM column to the whole column with well depth during CBM producing process in pumping wellbores. The ratio of flowing pressure is a function of 


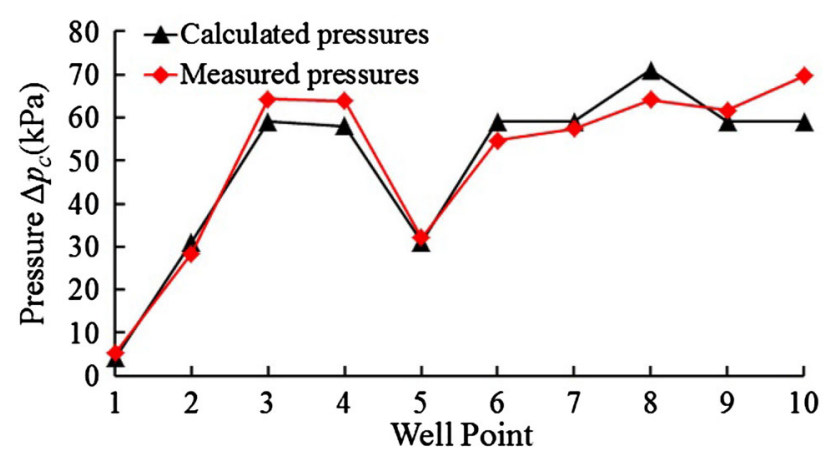

(a) Flowing pressures of CBM column

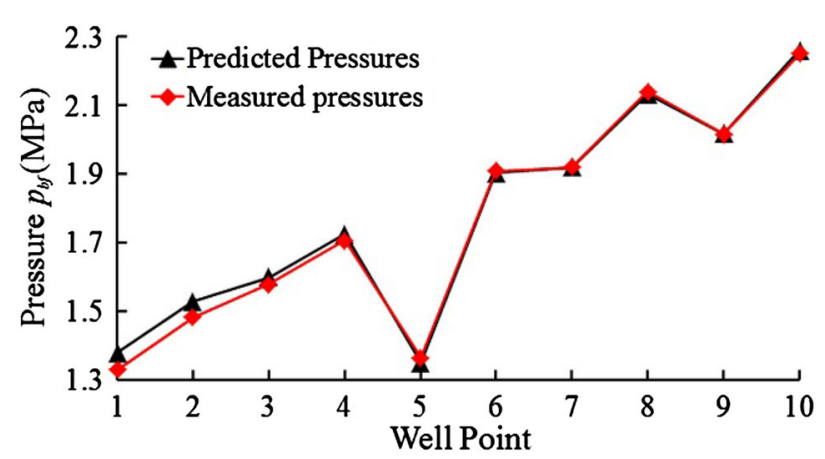

(b) Bottom-hole pressures

Fig. 2 Comparison of flowing pressures between predicted and measured results in single-phase CBM wellbores

dynamic water level along the annulus. The ratios of flowing pressure on increment of CBM column to the whole column are relatively high during the phase of single-phase CBM flow. And the average ratio of flowing pressure is calculated to be $32 \%$. Consequently, the effect of CBM column pressure should not be neglected during the process of predicting flowing pressures along the annulus. At the same time, the effect of flowing pressure on CBM column is more obvious than that on CBM and water

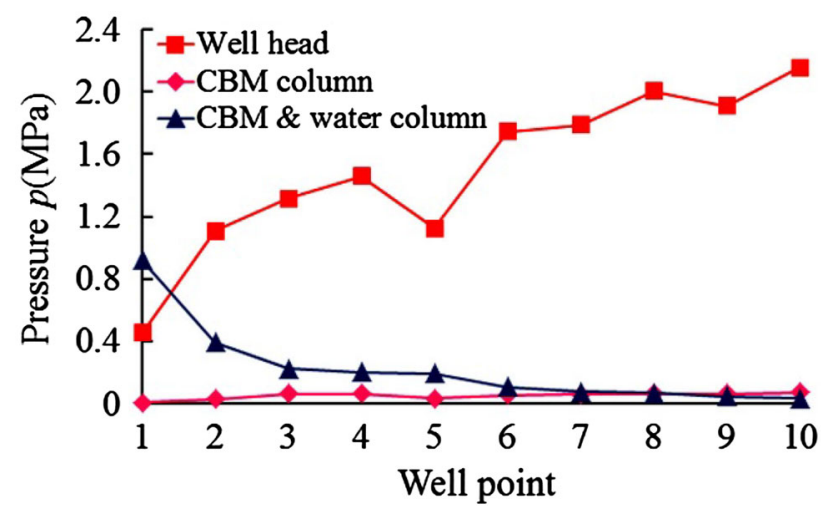

Fig. 3 The variation of flowing pressures with pumping time along the annulus in wellbores

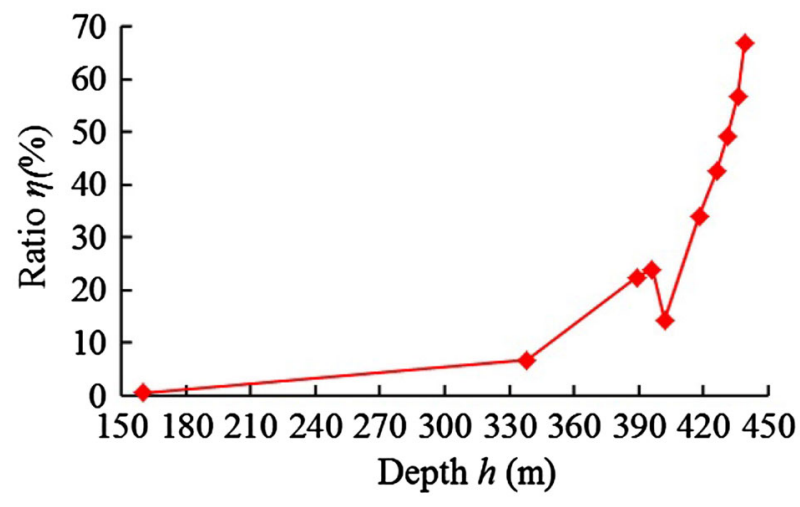

Fig. 4 The ratios of flowing pressure on increment of CBM column to the whole column along the annulus

column accompanied by an increase of dynamic water level. The ratios of flowing pressure on increment of CBM column to the whole column increase with the declined flow rates of water column. The ratios of flowing pressure enhance from $0.6 \%$ to $24 \%$ and then up to $67 \%$ while dynamic water levels along the annulus increase from $160 \mathrm{~m}$ to $439 \mathrm{~m}$.

Figure 5 depicts the relationships between flowing pressure of CBM column and CBM production in singlephase CBM wellbores. The bottom-hole pressure enhances accompanied by an increase of flowing pressure of CBM column along the annulus. And this will lead to the results of the declined CBM production in single-phase CBM wellbores. It can be seen from the figure that flow rates of CBM column enhance from 3327 to $6721 \mathrm{~m}^{3} / \mathrm{d}$ with the declined pressures of CBM column from 69.7 to $5.2 \mathrm{kPa}$ along the annulus.

Figure 6 shows the effect of pressure drops on flow rate of CBM column along the annulus in single-phase CBM wellbores. The flow rate of CBM column is a function of pressure drop between bottom-hole pressure and Langmuir pressure along the annulus. There is a positive proportion between pressure drop and flow rate of CBM column. The

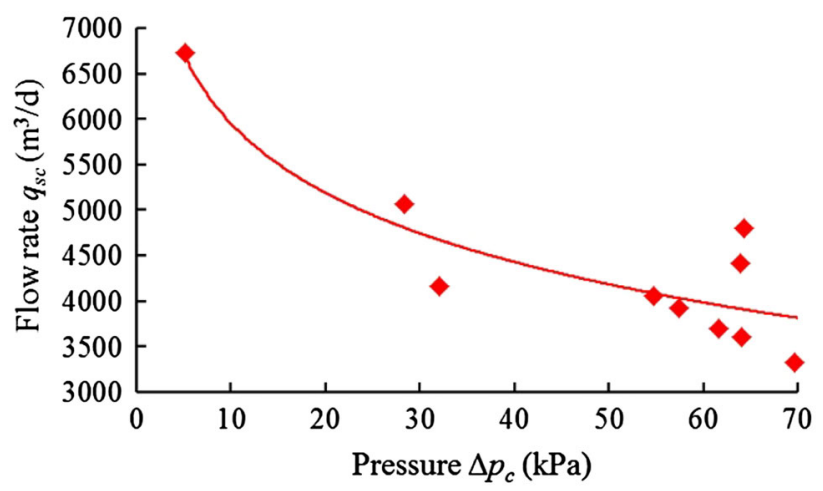

Fig. 5 The effect of flowing pressure on flow rate of CBM column along the annulus in wellbores 


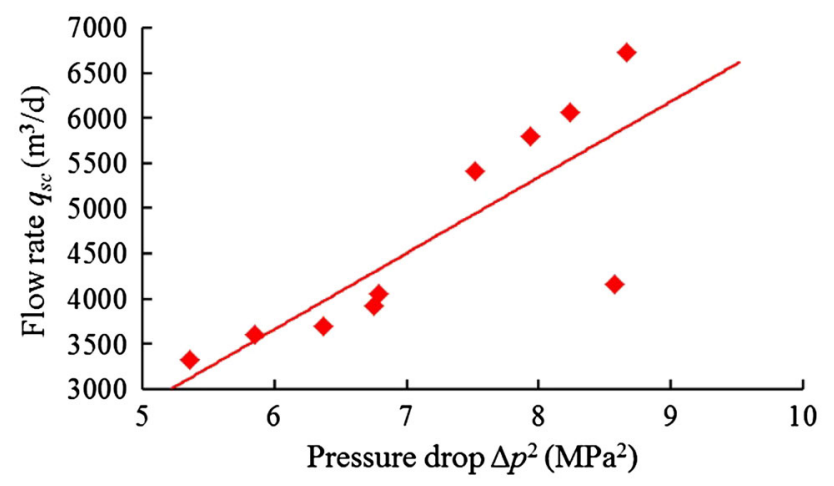

Fig. 6 The effect of pressure drop on flow rate of CBM column along the annulus in wellbores

increased pressure drop of CBM column is beneficial to CBM desorption in coal reservoirs, leading to the results of the improved CBM flow rate in single-phase CBM wellbores. The flowing pressures of CBM column and CBM and water column enhance the imbalance of pressure between well head and bottom hole in single-phase CBM wells. Flow rates of CBM column vary in a large scale with pressure drops of CBM column during CBM producing process. It can be seen from Fig. 6 that there is a point $\left(8.58 \mathrm{MPa}^{2}, 4162 \mathrm{~m}^{3} / \mathrm{d}\right)$ that clearly deviates from the straight line. The main reason is that the decreased flowing pressures of well head and CBM column and the increase of the falling speed of dynamic water level will reduce bottom-hole pressure and enhance the imbalance of pressure drop.

\section{Conclusions}

This work presents a methodology that involves a numerical integration technique to predict and analyze the dynamic characteristics of CBM column in wellbores. This provides the theoretical basis to analyze the dynamic behavior in CBM reservoir and process of CBM flow and solve the forthcoming problems in single-phase CBM wellbores. It comes out that:

(1) The calculating process of flowing pressures involves friction factor with variable Reynolds number and CBM temperature and compressibility factor with gravitational gradients. The developed relationships are validated against full-scale measured data in single-phase CBM wellbores.

(2) Well-head pressure, pressure drop of CBM column and CBM and water column, and bottom-hole pressure along the annulus can fully reflect dynamic characteristics of CBM producing process because of the combination of dynamic water level and flow rates of CBM column and water column.
(3) The effect of flowing pressure on CBM column is more obvious than that on CBM and water column accompanied by an increase of dynamic water level. The ratios of flowing pressure on increment of CBM column to the whole column increase from $0.6 \%$ to $24 \%$ and then up to $67 \%$ while dynamic water levels along the annulus increase from 160 to $439 \mathrm{~m}$.

(4) The decreased pressures of CBM column from 69.7 to $5.2 \mathrm{kPa}$ will lead to the results of the decreased bottom-hole pressures from 2.3 to $1.3 \mathrm{MPa}$ and the increased flow rates of CBM column from 3327 up to $6721 \mathrm{~m}^{3} / \mathrm{d}$.

Acknowledgements This work was financially supported by National Science and Technology Major Project of the Ministry of Science and Technology of China (2016ZX05065-001), Key Research Project of Shandong Province (2019GHY112029 and 2019GSF109090) and Higher Education Research and Development Project of Shandong Province (J17KA033).

Open Access This article is distributed under the terms of the Creative Commons Attribution 4.0 International License (http://crea tivecommons.org/licenses/by/4.0/), which permits unrestricted use, distribution, and reproduction in any medium, provided you give appropriate credit to the original author(s) and the source, provide a link to the Creative Commons license, and indicate if changes were made.

\section{References}

Ashena R, Moghadasi J (2011) Bottom hole pressure estimation using evolved neural networks by real coded ant colony optimization and genetic algorithm. J Pet Sci Eng 77(4):375-385

Bello O, Asafa T (2014) A functional networks softsensor for flowing bottomhole pressures and temperatures in multiphase production wells. In: SPE intelligent energy conference \& exhibition, pp 881-895

Boltenko EA (2013) Determination of the density and flow rate of the two-phase mixture under steady and emergency conditions. Therm Eng 60(3):195-201

Borowsky J, Wei T (2006) Simultaneous velocimetry/accelerometry measurements in a turbulent two-phase pipe flow. Exp Fluids 41(1):13-20

Clarkson CR, Bustin RM, Seidle JP (2007) Production-data analysis of single-phase (gas) coalbed-methane wells. SPE Reserv Eval Eng 10(3):312-331

Cullender MH, Smith RV (1956) Practical solutions of gas-flow equation for wells and pipelines with large temperature gradients. Trans AIME 207:281-287

Fan LM, Ma LQ, Yu YH, Wang SK, Xu YJ (2019) Water-conserving mining influencing factors identification and weight determination in northwest China. Int J Coal Sci Technol 6(1):95-101

Guzman JD, Arevalo JA, Espinola O (2014) Reserves evaluation of dry gas reservoirs through flowing pressure material balance method. In: SPE energy resources conference, pp 989-1002

Langelandsvik LL, Postvoll W, Svendsen P, Overli JM (2005) An evaluation of the friction factor formula based on operational data. In: Pipeline simulation interest group (PSIG) annual meeting, pp 505-520 
Li Z, Hovakimya N, Kaasa GO (2017) Bottom hole pressure estimation and $\mathrm{L} 1$ adaptive control in managed pressure drilling system. Int J Adapt Control Signal Process 31(4):545-561

Liu XF (2013) Prediction of flowing bottomhole pressures for twophase coalbed methane wells. Acta Geol Sin-Engl 87(5):1412-1420

Liu XF, Liu CH, Qi YG (2017) Operating performance of sucker rod pump for the pumping system in coalbed methane wells. J Mech Eng 53(8):195-200

Liu XF, Liu CH, Wu JJ, Qi YG (2018) Migration models of pulverized coal flowing with fluid and its production in CBM channels for the coal reservoirs. J China Coal Soc 43(3):770-775

Liu XF, Liu CH, Wu JJ (2019) A modern approach to analyzing the flowing pressures of a two-phase CBM and water column in producing wellbores. Geofluids 2019(4):1-9

Liu XF, Qi YG, Hu AM, Zhao PH, Liu CH (2011) Inflow performance relationship in two-phase CBM wells. J China Univ Min Technol 40(4):561-591

Lyubarskii SD, Ivanov S (1989) Motion of a compressed two-phase medium of bulk density upon sudden expansion. Explos Shock Waves 25(3):335-337

Mattar L, McNeil R (1998) The "flowing" gas material balance. J Can Pet Technol 37(2):287-291

Menad NA, Nourddine Z, Kheireddine R (2018) Bottom hole pressure estimation using hybridization neural networks and grey wolves optimization. Petroleum 4(4):419-429

Mitchell R (2011) Casing design with flowing fluids. SPE Drill Complet 26(3):432-435

Mohammadpoor M, Shahbazi K, Firouz ARQ (2010) Vertical multiphase flow in Iranian oil fields using artificial neural networks. In: SPE Latin American and caribbean petroleum engineering conference, pp 147-156

Mohammed S, Enty GS (2013) Analysis of gas production data using flowing material balance method. In: SPE Nigeria annual international conference and exhibition, pp 258-279

Mohammed S, Jeje O, Louis M (2011) Advanced gas material balance in simplified format. J Can Pet Technol 50(1):90-98

Mora CA, Wattenbarger RA (2009) Analysis and verification of dual porosity and CBM shape factors. J Can Pet Technol 48(2):17-21

Obeida TA, Mosallam YH (2007) Calculation of flowing bottom-hole pressure constraint based on bubble point pressure versus depth relationship. In: EUROPEC/EAGE conference and exhibition, pp 58-62

Okuszko KE, Gault BW, Mattar L (2008) Production decline performance of CBM wells. J Can Pet Technol 47(7):913-917

Osman SA, Aggour MA (2002) Artificial neural network model for accurate prediction of pressure drop in horizontal-multiphase flow. Pet Sci Technol 20(1):1-15
Osman SA, Ayoub MA, Aggour MA (2005) An artificial neural network model for predicting bottomhole flowing pressure in vertical multiphase flow. In: SPE middle east oil and gas show and conference, pp 913-920

Peffer JW, Miller MA, Hill AD (1988) An improved method for calculating bottomhole pressures in flowing gas wells with liquid present. SPE Prod Eng 3(4):643-655

Rendeiro CM, Kelso CM (1988) An investigation to improve the accuracy of calculating bottomhole pressures in flowing gas wells producing liquids. In: Permian basin oil and gas recovery conference, pp 307-316

Smith JA, Ramandi HL, Zhang CG, Timms W (2019) Analysis of the influence of groundwater and the stress regime on bolt behaviour in underground coal mines. Int J Coal Sci Technol 6(2):286-300

Sugiarto I, Mazumder S, Wittemeier R, Sharma V (2015) Inflow performance relationship correlation of 2 phase CBM reservoir. In: SPE/IATMI Asia pacific oil \& gas conference and exhibition, pp 185-199

Sutton RP (2008) An accurate method for determining oil PVT properties using the Standing-Katz gas Z-factor chart. SPE Reserv Eval Eng 11(2):246-266

Tang S, Liu CX, Dong YH (2016) Multiphase flow model developed for simulating gas hydrate transport in horizontal pipe. Appl Math Mech 37(9):1193-1202

Towler B, Firouzi M, Underschultz JR (2016) An overview of the coal seam gas developments in Queensland. J Nat Gas Sci Eng 50(4):249-271

Underschultz JR, Vink S, Garnett A (2018) Coal seam gas associated water production in Queensland: actual vs predicted. J Nat Gas Sci Eng 52(4):410-422

Vicki AH, Paul SS (2002) A guide to coalbed methane operations. Gas Res Inst, Alabama

Wang RH, Huo HJ, Huang ZY, Song HF, Ni HJ (2014) Experimental and numerical simulations of bottom hole temperature and pressure distributions of supercritical $\mathrm{CO}_{2}$ jet for well-drilling. J Hydrodyn 26(2):226-233

White AH, Smith FT (2012) Wall shape effects on multiphase flow in channels. Theoret Comput Fluid Dyn 26(1):339-360

Yalniz MU, Ozkan E (2001) A generalized friction factor correlation to compute pressure drop in horizontal wells. SPE Prod Facil 16(4):232-239

Yao YD, Ge JL (2011) Characteristics of non-Darcy flow in lowpermeability reservoirs. Pet Sci 8(1):55-62 